Sturge-Weber syndrome (SWS), during work-up for possible epilepsy surgery at Great Ormond Street Hospital and The Institute of Child Health, London, UK. The infants presented with recurrent seizures, altered consciousness, and neurologic deficits, and two showed clinical and radiological progression of the encephalopathy. SPECT showed hemispheric hypoperfusion, and middle cerebral artery velocity (MCAV) was reduced by $30-60 \%$ in the affected hemisphere compared with the contralateral side. MCAV during seizures was increased from 6 to $30 \%$ in the involved hemisphere compared to $24-179 \%$ for the contralateral side. This hemodynamic response to seizures of the unaffected hemisphere appeared to decrease over time, leading to increased cognitive and neurologic deficits with further seizure episodes. Abnormalities of the venous circulation in SWS, with reduced capacity for increasing venous return, cause venous hypertension and chronic progressive ischemia. (Aylett SE, Neville BGR, Cross JH, Boyd S, Chong WK, Kirkham FJ. Sturge-Weber syndrome: cerebral haemodynamics during seizure activity. Dev Med Child Neurol July 1999;41:480-485). (Respond: Dr FJ Kirkham, Neurosciences Unit, Institute of Child Health, The Wolfson Centre, Mecklenburgh Square, London WC1N 2AP, UK).

COMMENT. Sturge-Weber syndrome is characterized by epilepsy, hemiparesis, and pial and facial angiomata. The onset of seizures is often associated with neurologic deterioration and learning disability. The hemisphere underlying the venous angioma shows progressive gliosis, atrophy, and calcification, compatible with ischemia. The present study of the cerebral hemodynamics, in both affected and contralateral hemispheres, during seizure activity elucidates the cause of the progressive ischemia and neurologic deterioration in SWS. The progressive nature of the SWS encephalopathy after seizure onset, and especially in cases complicated by status epilepticus, should prompt consideration of early surgical excision. (see Progress in Pediatric Neurology I, PNB Publ, 1991;pp38-39, for report of progressive mental impairment in SWS).

Cutaneous mosaicism of lethal mutations and the lethal gene concept is proposed for Sturge Weber and other neurocutaneous syndromes (Hamm H. Am I Med Genet Aug 1999;85:342-345). SWS is a non-hereditary disorder. The concept of autosomal lethal genes surviving only in a mosaic state is proposed to explain the genetic basis of syndromes such as SWS, characterized by sporadic occurrence, distribution of lesions in an asymmetrical pattern, lack of diffuse involvement of entire organs, and equal sex ratio.

The Sturge-Weber Foundation currently announces a new book on SWS, edited by Bodensteiner JB and Roach ES.

\title{
MAGNETIC RESONANCE SPECTROSCOPY IN NEUROFIBROMATOSIS
}

The functional significance of T2 hyperintense lesions (UBOs) and their role in learning disabilities associated with neurofibromatosis type 1 (NF-1) were studied by quantitative magnetic resonance spectroscopy (MRS) in 7 male patients, aged 6-19 years, and 7 controls, at Johns Hopkins University, Baltimore, MD. Choline metabolite concentrations within UBOs, globus pallidus, and thalami were elevated in younger NF-1 subjects ( $<10$ years), and were normal in older patients. N-acetylaspartate (NAA) levels were preserved in younger subjects and reduced in older patients. NAA was also decreased in the periventricular white matter. The MRS metabolic abnormality in UBOs of NF-1 is representative of a more generalized abnormality in affected brain regions. Choline elevations, reflecting increased myelin turnover in edematous areas, is followed by axonal 
injury and reduced NAA. (Kaufmann WE, Wang PY, Koth CW, Denckla MB, Barker PB. Evaluation of brain metabolism in neurofibromatosis type 1 by magnetic resonance spectroscopy. Ann Neurol September 1999;46:528. CNS 28th Annual Meeting Abstract, Oct 13-16, 1999).

COMMENT. This work is an extension of previous reports from Johns Hopkins University concerning the relationship between UBOs and lower IQs in children with neurofibromatosis-1 (Denckla MB et al. Am I Med Genet 1996;67:98102). (see Progress in Pediatric Neurology III, PNB Publ, 1997;pp291-294, for a review of these and other reports, some showing conflicting results).

Ped Neur Briefs Nov 1997;11:84, reviews an article on learning disability subtypes in children with neurofibromatosis; academic underachievers fall into 3 groups: $40 \%$ have normal IQ test results, 50\% have general learning disabilities, and $14 \%$ have visuospatial and motor coordination problems, without language deficits.

\section{HYPOMELANOSIS OF ITO: A GENETIC MOSAICISM}

Evidence purporting that the so-called hypomelanosis of Ito (HI) syndrome does not exist as a distinct multisystem birth defect is presented by geneticists and dermatologists at Bad Salzschlirf, and Philipp University of Marburg, Germany. HI is a nonspecific pigmentary disorder representing a cutaneous marker of many different states of genetic mosaicism. The clinical findings are highly variable, not always involving brain, eyes or bones, occurrence is sporadic, and cytogenetic abnormalities involve many different chromosomes, especially the Xchromosome. The terms $\mathrm{HI}$, incontinentia pigmenti achromians, pigmentary dysplasia, and pigmentary mosaicism are synonyms of the same cutaneous signs. "Pigmentary mosaicism of the Ito type" should be substituted for the term "HI syndrome."(Kuster W, Konig A. Hypomelanosis of Ito: No entity, but a cutaneous sign of mosaicism. Am I Med Genet Sept 1999;85:346-350). (Respond: Wolfgang Kuster MD, Clinical Genetics, TOMESA Clinic for Allergy, RiedstraBe 18, D-36361, Bad Salzschlirf, Germany).

COMMENT. HI is a relatively common disorder in pediatric neurology clinics, involving 1 in every 1000 patients attending a service in Spain (PascualCastroviejo I et al. Hypomelanosis of Ito; neurological complications in 34 cases. Can I Neurol Sci 1988;15:124-129). CNS anomalies include mental and motor retardation, microcephaly, hypotonia, hyperkinesia, ataxia, seizures, and deafness. Eye defects include microphthalmia, ptosis, nystagmus, cataracts, and retinal degeneration. Bone anomalies include dental enamel defects, short stature, limb asymmetry, scoliosis, syndactyly, and polydactyly. These multisystem defects are explained, not as a single syndrome, but by different genetic defects and a sign of mosaicism, as evidenced by a variety of reported underlying chromosomal abnormalities.

\section{MOVEMENT DISORDERS}

\section{TOURETTE SYNDROME AND DYSTONIA: GENETICALLY RELATED}

A three-generation family in which 5 members were diagnosed with focal dystonia and 3 with tics, Tourette syndrome, and hyperactivity is reported from the Radcliffe Infirmary, Oxford, and Queen Elizabeth Hospital, Birmingham, England. One with dystonic head tremor subsequently died of a motor neuron disease. The findings of dystonia and Tourette syndrome in 8 members of a single 